\title{
Avaliação do entendimento da cartilha educativa sobre TDAH em formato de revista em quadrinhos com educadores
}

\author{
Assessment of understanding of the educational booklet on ADHD in comic book format with \\ educators
}

Evaluación de la comprensión del folleto educativo sobre TDAH en formato de cómic con los educadores

\begin{abstract}
Resumo
O presente estudo teve como objetivo realizar a avaliação do entendimento da cartilha educativa em formato de revista em quadrinhos com educadores. A metodologia utilizada na pesquisa de campo foi descritiva, com abordagem qualitativa, participaram do estudo 64 docentes, a coleta de dados aconteceu por meio dos aplicativos WhatsApp e Messenger com o envio da cartilha educativa em Portable Document Format - PDF e o questionário com 13 perguntas com posterior análise discursiva. Os dados serviram como suporte para a elaboração de uma cartilha educativa quadrinizada sobre o Transtorno de Déficit de Atenção e Hiperatividade - TDAH, a ser utilizado pelos educadores. Os resultados obtidos reforçaram a importância de compreender os aspectos do comportamento da criança com TDAH, por meio do entendimento do transtorno. Acredita-se que a cartilha educativa poderá contribuir para o conhecimento dos educadores acerca do Transtorno de Déficit de Atenção e Hiperatividade, fornecendo-lhes subsídios para lidarem com os estudantes portadores do transtorno.
\end{abstract}

Palavras-chave: Transtorno de déficit de atenção com hiperatividade; Docentes; Ensino-aprendizagem.

\begin{abstract}
This study aimed to assess the understanding of the educational booklet in a comic book format with educators. The methodology used in the field research was descriptive, with a qualitative approach, 64 teachers participated in the study, data collection took place through the WhatsApp and Messenger applications with the sending of the educational booklet in Portable Document Format - PDF and the questionnaire with 13 questions with subsequent discursive analysis. The data served as support for the elaboration of an educational booklet on Attention Deficit Hyperactivity Disorder, which contains theoretical material to be used by educators with children who have this disorder. The results obtained reinforced the importance of understanding aspects of the behavior of students with ADHD, through the understanding of the disorder. It is believed that the educational booklet can contribute to the knowledge of educators about Attention Deficit Hyperactivity Disorder, providing them with subsidies to deal with students with the disorder.
\end{abstract}

Keywords: Attention deficit disorder with hyperactivity; Teachers; Teaching-learning. 


\begin{abstract}
Resumen
Este estudio tuvo como objetivo evaluar la comprensión del folleto educativo en formato de cómic con los educadores. La metodología utilizada en la investigación de campo fue descriptiva, con un enfoque cualitativo, 64 profesores participaron del estudio, la recolección de datos se realizó a través de las aplicaciones WhatsApp y Messenger con el envío del cuadernillo educativo en Formato de Documento Portátil - PDF y el cuestionario con 13 preguntas con posterior análisis discursivo. Los datos sirvieron de soporte para la elaboración de un folleto educativo sobre el Trastorno por Déficit de Atención e Hiperactividad - TDAH, para ser utilizado por los educadores. Los resultados obtenidos reforzaron la importancia de comprender aspectos de la conducta de los niños con TDAH, a través de la comprensión del trastorno. Se cree que el folleto educativo puede contribuir al conocimiento de los educadores sobre el Trastorno por Déficit de Atención con Hiperactividad, brindándoles subsidios para atender a los estudiantes con el trastorno.
\end{abstract}

Palabras clave: Trastorno por déficit de atención con hiperactividad; Profesores; Enseñanza-aprendizaje.

\title{
1. Introdução
}

Registram-se desde a Antiguidade (Rodrigues, 2018) inúmeras denominações para o Transtorno de Déficit de Atenção e Hiperatividade, que é considerado um transtorno neurobiológico. Ao longo do tempo, o TDAH recebeu várias nomenclaturas e a cada estudo e a cada nova hipótese, surgiram novas terminologias, mostrando que houve avanços nos diferentes aspectos do transtorno.

Em virtude de diversas pesquisas e estudos, o TDAH passou a ser considerado por diversos autores, pesquisadores e especialistas como um problema neurobiológico, de origem genética, com início na infância, persistindo na vida adulta.

Trata de um transtorno caracterizado, sobretudo, pela dificuldade de manter a atenção devido à inquietude e à agitação, podendo configurar um quadro de hiperatividade e impulsividade, principalmente no contexto escolar, sendo o ambiente de maior possibilidade de observação do comportamento e do desenvolvimento cognitivo do estudante, que manifesta os primeiros sintomas de desenvolvimento inadequado e dificuldades comportamentais, quando comparado com outros colegas da mesma sala de aula para a detecção do TDAH (Rocha et al., 2020).

Profissionais da educação não consideram o TDHA um transtorno, confundindo os comportamentos desajustados com indisciplina, sobretudo quando o estudante se destaca negativamente em sala de aula, prejudicando não somente a ele, mas toda a turma (Martinhago \& Caponi, 2019).

Diante do que foi exposto e no exercício da docência, ao perceber o aumento de casos de estudantes diagnosticados com TDAH e o desconhecimento por parte dos educadores sobre o transtorno, percebeu-se a necessidade de analisar o entendimento dos educadores em relação ao tema.

Com base no contexto descrito, desenvolveu-se uma ferramenta com vistas à produção de conhecimento, de modo que o processo de ensino-aprendizagem possa ser otimizado para o discente portador de Transtorno de Déficit de Atenção e Hiperatividade.

Na perspectiva de produzir uma reflexão sobre como o processo de ensino-aprendizagem poderia ser otimizado no processo educacional do discente portador do TDAH, foi formulada a seguinte questão problema para esta investigação: Qual é o método de ensino-aprendizagem eficaz para abordar o tema TDAH junto aos professores do ensino médio?

Norteados por esta questão, acredita-se que uma cartilha educativa em formato de história em quadrinhos, com vistas à produção de conhecimento, poderá ser um instrumento lúdico e de fácil compreensão para a abordagem deste assunto complexo e pouco explorado nas escolas.

O estudo teve como objetivo realizar a avaliação do entendimento da cartilha educativa em formato de revista em quadrinhos com educadores. 
Considera-se que a ferramenta educativa poderá contribuir para o cotidiano dos professores, dando-lhes suporte no processo de ensino-aprendizagem de estudantes com TDAH, visto que, quanto maiores os conhecimentos sobre o transtorno, melhores serão as estratégias pedagógicas estabelecidas para estes estudantes.

\section{Metodologia}

O tipo de estudo foi descritivo, com abordagem qualitativa. Nos estudos qualitativos, os fatos são observados, descritos e documentados. Na pesquisa qualitativa o pesquisador procura reduzir a distância entre a teoria e os dados, entre o contexto e a ação, usando a lógica da análise fenomenológica, isto é, da compreensão dos fenômenos pela sua descrição e interpretação (Sodré, 2014).

A coleta de dados ocorreu no mês de maio de 2020. A amostra foi composta por 64 professores que lecionam ou já lecionaram no ensino médio.

Para a coleta de dados, foram enviados, por meio dos aplicativos WhatsApp e Messenger, a cartilha educativa em PDF, para leitura dos participantes; o Termo de consentimento Livre e Esclarecido - TCLE; e o questionário com 13 perguntas, sendo cinco referentes à caracterização dos sujeitos, incluindo as variáveis sexo, formação, tempo de atuação, leciona ou lecionou no ensino médio e se já teve aluno portador do TDAH, quatro relativas à estrutura e apresentação da cartilha, e quatro sobre a relevância do material.

Para a aplicação e avaliação da cartilha educativa, foram elaborados um modelo de cartilha em formato PDF; um questionário on-line; e um Termo de Consentimento Livre e Esclarecido (TCLE), criado no Microsoft Forms. O acesso foi realizado pelo link: https://forms.office.com/Pages/ResponsePage.aspx?id=DQSIkWdsW0yxEjajBLZtrQAAAAAAAAAAA AYAAJkkv_dUMVdVOUhJMlowNzUzQ1AzTkFLVVZETTRXTS4u.

Após a leitura e concordância do TCLE, e a caracterização dos participantes, estes responderam às perguntas concernentes à estrutura, apresentação e relevância da cartilha, e para cada um desses itens foi estipulado um critério para quando as propriedades da cartilha eram totalmente alcançadas (concordo), quando eram parcialmente alcançadas (concordo parcialmente), quando não eram consideradas alcançadas (discordo) e quando eram parcialmente adequadas (discordo parcialmente).

Os dados coletados foram categorizados de acordo com a proposta por Minayo et al. (2012), que parte das seguintes fases: leitura exaustiva do material e pré-análise do mesmo; extração das palavras chaves e unidades temáticas; construção dos eixos temáticos e categorização para análise e interpretação dos mesmos. Segundo Minayo et al. (2012) a técnica de categorização é aquela que se têm dados construtivos, estruturando - se a partir de lógicas de acordo com o seu objetivo e são constituídas por estudos básicos que ajudam a desenvolver projetos.

Esta pesquisa foi aprovada pelo Comitê de Ética em Pesquisa do Hospital Municipal Dr. Munir Rafful / RJ sob o número CAAE - 24826819.0.0000.5255.

\section{Resultados e Discussão}

Os resultados foram extraídos por meio das respostas inseridas no aplicativo Microsoft Forms, permitindo observar o feedback individual dos avaliadores e, posteriormente, a realização da análise estatística dos resultados concernentes às críticas dos docentes. 


\section{A Cartilha Educativa sobre TDAH e o educador no contexto escolar}

A produção da cartilha deu-se através do desenvolvimento de uma dissertação, que foi apresentada à banca examinadora do Programa de Mestrado Profissional em Ensino em Ciências da Saúde e do Meio Ambiente de um Centro Universitário localizado em uma cidade do interior do Estado do Rio de janeiro.

O produto elaborado como ferramenta educativa, cujo título é "Transtorno de Déficit de Atenção e Hiperatividade TDAH: como lidar? - O conhecimento como ferramenta para o professor", foi fundamentado nos estudos de especialistas que investigaram as dificuldades rotineiras enfrentadas pelos educadores junto aos portadores do TDAH (Rocha et al., 2020). Com essas observações, pode-se notar no Quadro 1 a síntese das causas fundamentais para as principais dificuldades de convivência escolar com o distúrbio.

Quadro 1 - Causas de insucesso no convívio com portador de TDAH.

\begin{tabular}{|c|c|}
\hline INDICAÇÃO & CAUSAS DE INSUCESSO NO CONVÍVIO \\
\hline 1 & Desconhecimento da existência do transtorno \\
\hline 2 & Desconhecimento de conceito, comorbidades e tratamento \\
\hline 3 & Falha na aplicação de estratégia no relacionamento com aluno \\
\hline 4 & Falta de experiência no convívio com portador \\
\hline
\end{tabular}

Fonte: Autores (2020).

A intenção é que os professores se empenhem na identificação dos estudantes portadores do TDAH em suas salas de aula e, posteriormente, intercedam a favor destes estudantes.

A cartilha educativa em formato de história em quadrinhos e seu enredo apresentam conteúdos referentes ao TDAH, por meio de personagens e uma trama narrativa adaptada para tornar o conhecimento acessível.

Figura 1 - Capa.
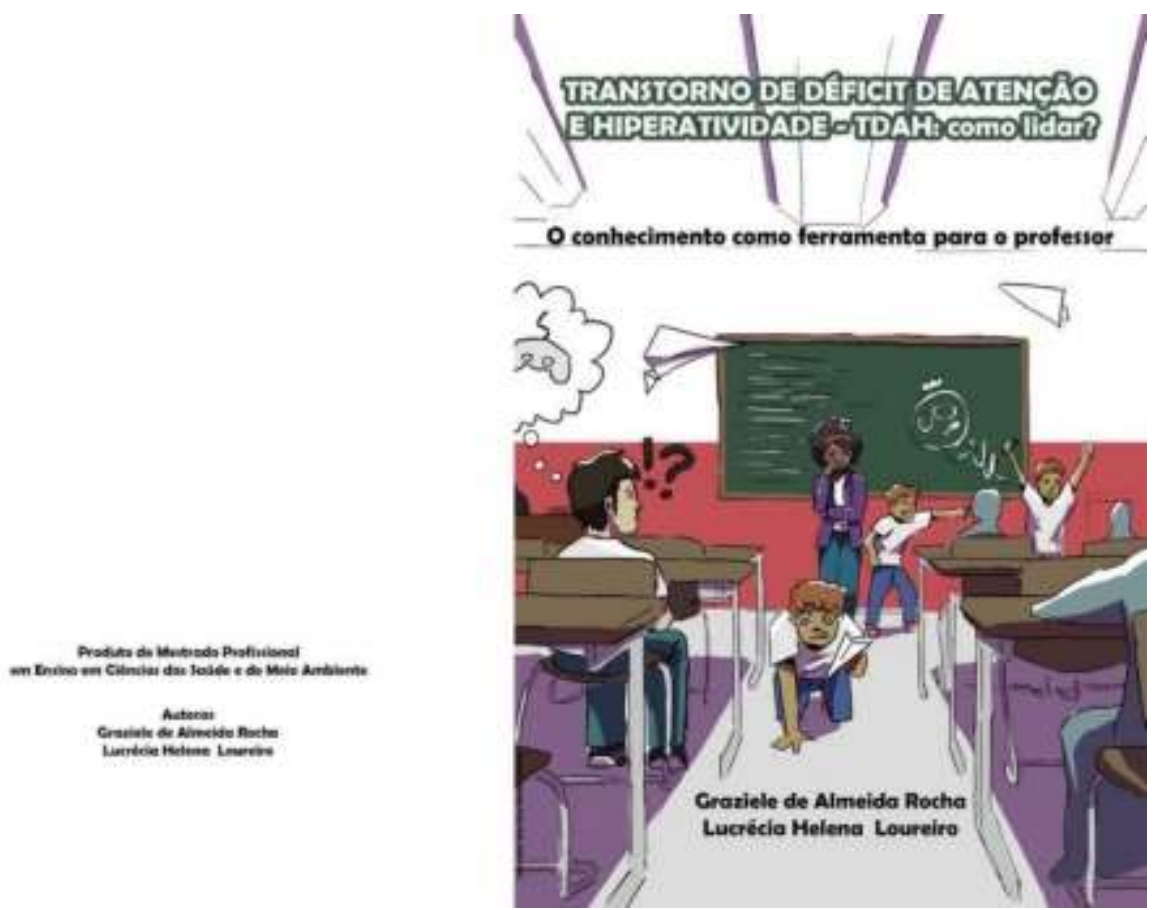

Fonte: Autores (2020). 
Na capa da cartilha (Figura 1), visualiza-se uma sala de aula, onde há um estudante sentado à esquerda, totalmente desconectado do ambiente, com o pensamento fora do contexto escolar; outro aluno, que não sossega na carteira, movimentase o tempo todo, distrai os colegas, agita o ambiente, além da professora, que não compreende e não sabe o que fazer, e o título "Transtorno de Déficit de Atenção e Hiperatividade - TDAH: como lidar? - O conhecimento como ferramenta para o professor".

A história ocorre em um ambiente escolar, demonstra exatamente o que se passa com o estudante portador do TDAH. Na ilustração, veem-se dois estudantes que não estão atentos à aula, um devido à sua inquietação e agitação e o outro devido à sua desatenção e aos seus pensamentos voltados para diversas coisas, além da professora, que está chamando a atenção dos dois, identificando-os como um problema para a sua aula.

Há presença de fatores que convocam os educadores a iniciar a leitura da história, por exemplo, o comportamento dos estudantes, que os convidam, em uma cena que faz parte do seu cotidiano, a descobrir do que se trata o assunto.

A característica essencial do TDAH é um padrão persistente de desatenção e/ou hiperatividade-impulsividade que atinge o funcionamento ou o desenvolvimento do comportamento (Associação Americana de Psiquiatria, 2014).

Acredita-se que os professores, ao se depararem com estudantes portadores do TDAH, podem confundir o comportamento agitado e desatento com falta de educação e desinteresse e não saber lidar com eles em sala de aula, o que acaba prejudicando, de forma significativa, o processo de ensino-aprendizagem.

O professor tem um papel fundamental no processo de diagnóstico do TDAH, não sendo ele quem vai fazer o diagnóstico, mas sim quem deve/vai estar atento aos sinais de um possível TDAH (Arruda et al., 2019).

Em outra ilustração a professora queixa-se dos estudantes com a coordenadora educacional, pois esperava um comportamento padronizado dos alunos e, quando isto não ocorre, estes são tidos como rebeldes e desinteressados. Em sequência, a coordenadora educacional identifica que outros professores também apresentam queixas parecidas dos mesmos estudantes, bem como de outros de outras salas, que têm o mesmo comportamento. Neste trecho, atenta-se para a questão de que o TDAH é um desafio para os professores em razão de desconhecerem o transtorno e não saberem como lidar com esses estudantes. Desse modo, buscou-se demonstrar que vários estudantes apresentam comportamentos do TDAH, porém os professores têm dificuldade em identificar adequadamente o transtorno.

A cena ilustra que são frequentes as queixas dos professores em relação às conversas constantes, à inquietude, indisciplina e desmotivação durante as atividades, dentre outros comportamentos que chamam atenção em sala de aula.

No entanto, Pereira, Eduvirgem e Monteiro (2017) apontam que, em geral, esses professores não possuem o entendimento necessário sobre o TDAH, nem o requerido preparo para lidar com os alunos que possuem dificuldades decorrentes do transtorno.

Para lidar com o estudante portador do TDAH, o professor precisa previamente conhecer o transtorno e saber diferenciá-lo de falta de educação, desleixo, preguiça ou falta de comportamento (Maia \& Confortin, 2015). Nessa perspectiva, o professor tem papel fundamental no desenvolvimento das habilidades cognitivas e afetivas do estudante com TDAH (Arruda et al., 2019).

Acrescenta-se, também, que o educador deve ser instruído, tanto na formação inicial como na continuada, assim como ser amparado em sua prática pedagógica e ter conhecimento sobre o transtorno (Maia \& Confortin, 2015) e as estratégias adequadas a serem utilizadas em sala de aula para que esses estudantes sejam de fato inclusos na escola.

$\mathrm{O}$ educador deve ter em mente que o TDAH não se traduz apenas em hiperatividade. A ausência de informação sobre a temática pode levar o professor a tratar tais dificuldades com atitudes de senso comum. Professores informados e atualizados sobre a natureza e causa do TDAH tornam-se mais assertivos, auxiliando o estudante a desenvolver suas competências em sala de aula. 
Nas próximas ilustrações a especialista discorre sobre os sinais e sintomas do TDAH, sempre utilizando ilustrações dos comportamentos padrão, para que o professor possa imaginar de forma clara determinados comportamentos. Estas páginas da cartilha possibilitaram ao educador o entendimento em relação ao comportamento e às limitações do estudante com TDAH, substituindo a ideia de aluno preguiçoso, bagunceiro e desinteressado, por conceitos de dificuldades na atenção, hiperatividade e problemas de aprendizagem.

Vale ressaltar que a pessoa com TDAH deve enquadrar-se em seis ou mais dos nove itens de uma ou ambas as listas de sintomas (Santos, 2017) para desatenção ou hiperatividade/impulsividade. Os itens são os seguintes: a) desatenção: não presta atenção em detalhes, cometendo erros por descuido; dificuldade em manter a atenção na tarefa ou na brincadeira; não ouve quando alguém the dirige diretamente a palavra; não consegue terminar as tarefas escolares, os afazeres domésticos ou os deveres do trabalho; dificuldade em organizar atividades; evita atividades que requerem esforço mental prolongado; perde coisas; distrai-se facilmente; é esquecida; b) hiperatividade: inquietude ou se contorce na cadeira; sai do lugar quando se espera que permaneça sentada; corre de um lado para o outro; ruidosa; age como se fosse "movida a pilha"; fala em excesso; c) impulsividade: responde antes que a pergunta seja completada; dificuldade de esperar sua vez; interrompe os outros ou se intromete.

A cartilha segue com a especialista falando sobre o diagnóstico permitindo ao leitor identificar a necessidade do diagnóstico para que se tenham os parâmetros individuais necessários para acompanhar essa criança/aluno, assim como demonstra a importância da observação e do relato dos professores para indicar características atípicas do desenvolvimento/comportamento.

No processo diagnóstico do TDAH, a figura do professor é essencial, uma vez que, frequentemente, é ele quem nota os primeiros sintomas (Arruda et al., 2019). Por conseguinte, quanto mais bem informado e preparado o professor estiver, mais parâmetros terá para cumprir essa função.

O diagnóstico do TDAH é clínico, feito por meio de observações comportamentais dos indivíduos a partir dos critérios diagnósticos dos Manuais de Diagnóstico e Estatística das Perturbações Mentais (DSM-V), considerando a persistência e gravidade das manifestações dos sintomas relacionados ao transtorno (Pereira et al., 2017). Com estas informações, é possível fazer o diagnóstico e programar o tratamento adequado.

Em outro momento na cartilha a especialista cita as formas de tratamento do TDAH buscando diferenciar os tipos de tratamento, que serão baseados nas necessidades individuais. Quanto mais informações o portador do transtorno e as pessoas com quem ele convive tiverem, maior é a contribuição para a eficiência do tratamento.

A união dessas informações pode agregar muito conhecimento para os profissionais que lidam com o TDAH, sendo importante que o diálogo aconteça como forma de interação para troca de informações antes e durante o tratamento, com o propósito de reunir estratégias satisfatórias e eficazes no tratamento dos sintomas e que contemplem o indivíduo em sua integralidade.

Diante da multiplicidade de sintomas, tem-se um impacto significativo no desempenho acadêmico e nas relações sociais desse indivíduo. Desta forma, o acompanhamento e o processo de tratamento do TDAH requerem uma avaliação de diversos profissionais, dentre eles, médicos, psicólogos, psicopedagogos e fonoaudiólogos, assim como intervenções farmacológicas (Carvalho \& Santos, 2016). Além disso, os autores ressaltam a importância do apoio familiar como parte fundamental do tratamento.

Nas próximas páginas da cartilha, há ilustrações em que a especialista finaliza fornecendo algumas orientações que podem ser utilizadas com o estudante TDAH em sala de aula. As ilustrações, que trazem exemplos de comportamentos comuns do estudante com o transtorno e as orientações sobre como intervir, permitem que o professor identifique esses 
comportamentos e as estratégias diferenciadas que podem ser aplicadas para o estudante portador do TDAH, de forma que se tenham menos interferências, melhorando a participação do aluno durante as aulas.

O TDAH afeta o comportamento e a capacidade de aprendizagem. Diante disso, é imprescindível que a escola assuma o papel de organizar os processos de ensino a fim de favorecer ao máximo a aprendizagem do aluno portador do transtorno. Nesse sentido, é essencial que o professor conheça o TDAH e reconheça que esses estudantes necessitam de auxílio. A direção, coordenação, equipe técnica e professores da escola precisam planejar e implementar técnicas e estratégias de ensino para melhor atender às necessidades desses alunos (Associação Brasileira de Déficit de Atenção, 2011).

$\mathrm{Na}$ última ilustração da cartilha, novamente no ambiente da sala de aula, a professora ministra sua aula, utilizando algumas estratégias, como colocar os estudantes "problemáticos" sentados na primeira carteira, longe de possíveis estímulos e/ou distrações (janelas, colegas que possam de alguma forma incitar a agitação). A professora passou a adotar uma abordagem individual com os estudantes, regras claras e expostas no mural da sala. As imagens sugerem que, por meio do conhecimento/entendimento do TDAH, é possível oferecer um acompanhamento diferenciado para o estudante portador do transtorno. O educador, com base acadêmica e com o apoio da instituição, tem possibilidade de usar parâmetros para lidar com o estudante TDAH, visto que eles são essenciais para melhorar a qualidade do processo no ensino-aprendizagem.

O conhecimento é significativo por definição, para Puhl, Müller e Lima (2020), é o resultado de um processo psicológico cognitivo (saber) que cinge a relação entre ideias logicamente (culturalmente) significativas, ideias anteriores (ancoradas) da estrutura cognitiva do aprendiz (ou estrutura dos conhecimentos deste) e o mecanismo mental do mesmo, para aprender de forma significativa ou para adquirir e manter conhecimentos.

Conhecer e compreender o transtorno para saber diferenciá-lo de qualquer outro comportamento permite ao professor pensar em estratégias de como adaptar suas aulas, viabilizando práticas que estimulem a participação dos estudantes com TDAH, de modo a possibilitar que absorvam as informações de forma mais efetiva, evitando sua rápida dispersão (Reis \& Cort, 2016).

A postura daquele que ensina gera desafios por meio de competências e potencializa o estudante que converte o saber em habilidades. Pretende-se, desta maneira, proporcionar os incentivos necessários, a fim de provocar o interesse e manter a atenção dos estudantes de forma que eles não fiquem dispersos e alheios ao conteúdo ensinado em sala de aula.

\section{Avaliação do entendimento da cartilha educativa sobre o TDAH em formato de revista em quadrinhos com educadores.}

$\mathrm{O}$ foco do trabalho é o ensino médio; desta forma, foram selecionados 64 docentes avaliadores atuantes nas categorias: ensino médio e fundamental, ensino médio, e ensino médio e superior,

A cartilha foi explicada aos professores, e como cautela, nesta amostragem, foi orientado aos professores que fizessem uma reflexão sobre o assunto para que houvesse uma avaliação construtiva e ponderada referente aos desafios que o TDAH traz no convívio escolar. Deste modo, foi traçada uma régua qualitativa, conforme ilustra a Figura 2, descrevendo os atributos para classificação das opiniões individuais acerca do emprego do produto de instrução. 
Figura 2 - Atributos para avaliação da cartilha pelos professores.

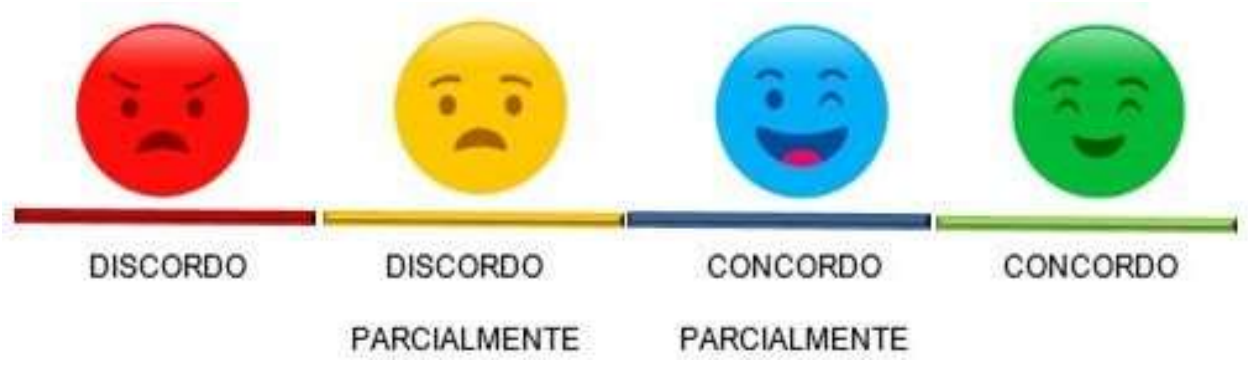

Fonte: Adaptado de EEZY INC. (2020).

Os atributos foram inseridos no aplicativo Microsoft Forms, permitindo observar o feedback individual dos avaliadores e, posteriormente, a realização da análise estatística dos resultados concernentes às críticas dos docentes.

Conforme exibido na Figura 3 pra a diversificação da amostra, como características dos avaliadores fez-se ainda a diferenciação por sexo e formação acadêmica em nível superior de ramos distintos, sendo exemplos: enfermagem, educação física, letras, matemática, pedagogia, dentre outras. Nota-se que $72 \%$ dos profissionais atuaram em turmas com presença de estudante portador de TDAH.

Figura 3 - Características dos profissionais participantes da amostragem.

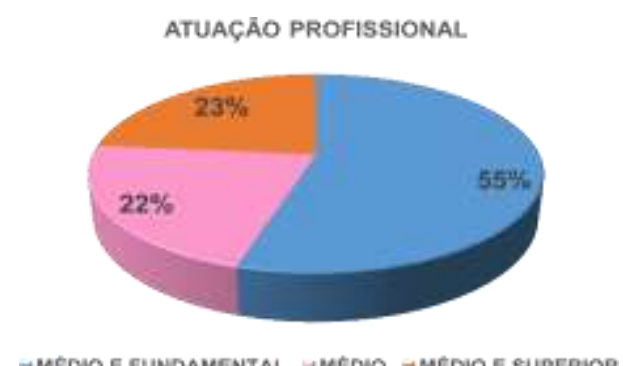

MEOHO E FUNDAMENTAL IMEOHO MMEOIO E SUPERIOR

SEXO BIOLOGICO DOS AVALIADORES

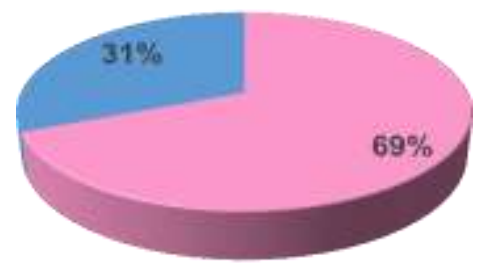

IAFEMININO IMASCULINO

Fonte: Autores (2020).

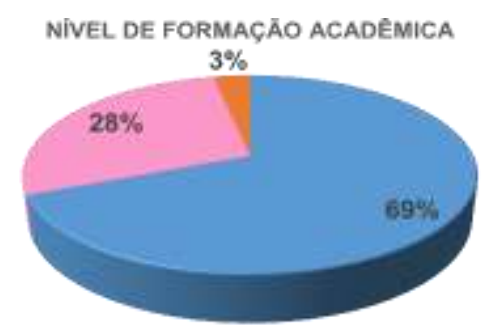

IGRADUACYAO IIPOSS GRADUACCAOO WDOUTORADO

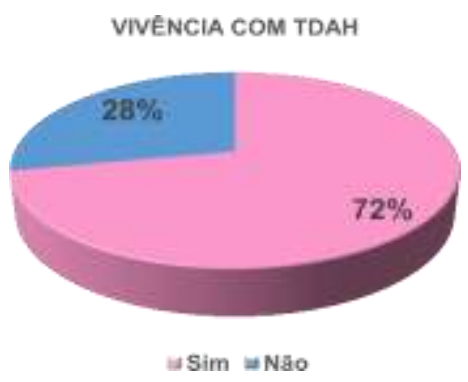

Assim sendo, diversos fatores mencionados na cartilha foram avaliados, como se observa nas Figuras 4 e 5, por meio dos arranjos das partes: estrutura e apresentação da cartilha e relevância da cartilha educativa.

Os gráficos da Figura 4, relativos à estrutura e apresentação da cartilha, estão dispostos de acordo com o ponto de vista de interpretação de Triola (2014), em que os gráficos de setores representam a divisão em segmentos e a proporção das ponderações sobre a cartilha. 
Figura 4 - Avaliação relativa à estrutura e apresentação da cartilha.

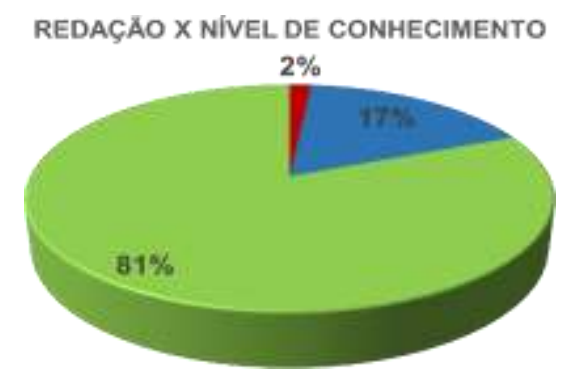

ILUSTRAÇŌES EXPRESSIVAS E SUFICIENTES

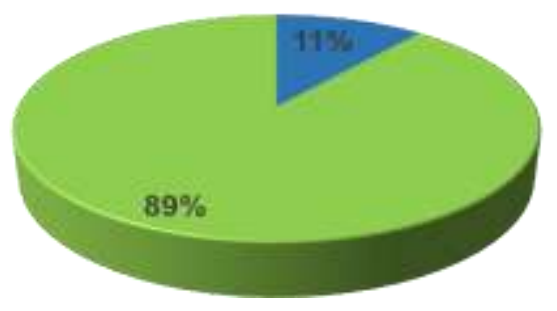

MENSAGENS CLARAS E OBJETIVAS

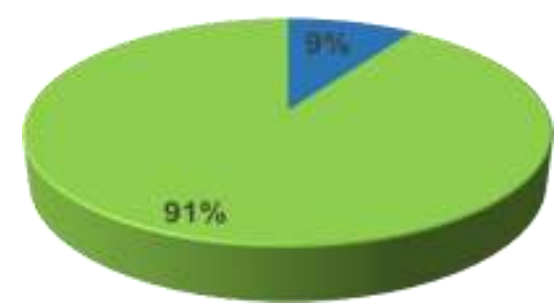

CARTILHA APROPRIADA PARA ORIENTAÇĀO

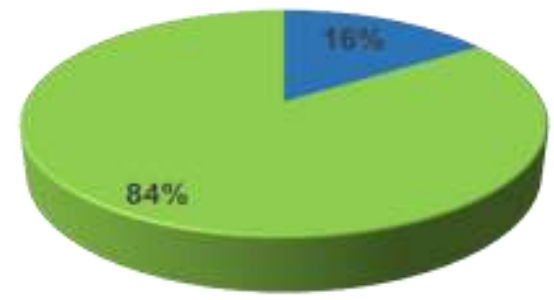

$\because$ DISCORDO

CONCORDO PARCIALMENTE $\triangle$ DISCORDO PARCIALMENTE

$\triangle$ CONCORDO

Fonte: Autores (2020).

O ponto positivo que mais chamou atenção entre o grupo de avaliadores foram as mensagens claras e objetivas, o que gera uma credibilidade durante a apresentação da ideia para públicos futuros, permitindo o entendimento da abordagem criada para aproximar estudante e professor.

Sabendo-se que as ilustrações são maneiras de interagir no aprendizado por meio de relações semânticas, a cartilha as utilizou para revelar valores sociais e sentimentos dos personagens, tendo também a coerência textual como alvo de boa aceitação pelos educadores. Entende-se que imagens de fácil compreensão e que retratem a realidade vivenciada pelo leitor, além de prenderem sua atenção, inserem-no na situação explanada, podendo tirá-lo da zona de conforto, dando início à prontidão para mudança de comportamento.

A função da cartilha é partilhar conhecimento como um veículo de disseminação de fundamentos sobre o TDAH. No transcorrer do período da aplicação da cartilha para os professores, ficou claro que ela cumpriu seu papel com a manipulação das ideias fundamentadas por esse meio de comunicação, podendo atingir públicos de forma on-line ou presencial.

A forma de redação em história em quadrinhos foi um pouco criticada em função do nível de conhecimento dos presentes avaliadores, mas a maioria dos presentes apreciou a comunicação visual pela forma rápida de captação das informações.

Os gráficos da Figura 5 também foram traçados no formato de gráficos de setores, porém, tiveram o objetivo de retratar a relevância da cartilha educativa no cotidiano, durante a aplicação das aulas dos docentes com as suas turmas. 
O destaque em questão foi que o tema proposto na cartilha retratou os aspectos-chaves necessários, proporcionando um reforço conceitual junto aos professores. Desta forma, os docentes se sentem mais seguros em tratar as questões do TDAH com familiares e propor ações conjuntas com as famílias, motivando o estudante a aprender e aumentando sua autoestima. Esse nível de aceitação foi de extrema importância, visto que vários autores estudados descrevem o desconhecimento do assunto pelos educadores.

Grande parte das críticas foi positiva em relação aos conhecimentos adquiridos entre os avaliadores, em que estes mostraram-se satisfeitos com as capacidades e conquistas alcançadas após a aplicação da ferramenta de aprendizado em questão, sentindo-se capazes de oferecer à instituição de ensino o apoio necessário para lidar com as limitações dos estudantes com TDAH.

O contexto da cartilha contribuiu para que o esclarecimento de dúvidas fosse realizado, sendo demonstrado por meio dos exemplos do comportamento humano em situações corriqueiras ocorridas dentro de sala de aula, o que gerou empatia aliada à correlação do cotidiano encontrado pelo profissional de educação, auxiliando o profissional a traçar novas abordagens pedagógicas estratégicas quando caracterizado o transtorno comportamental.

Figura 5 - Avaliação da relevância da cartilha.
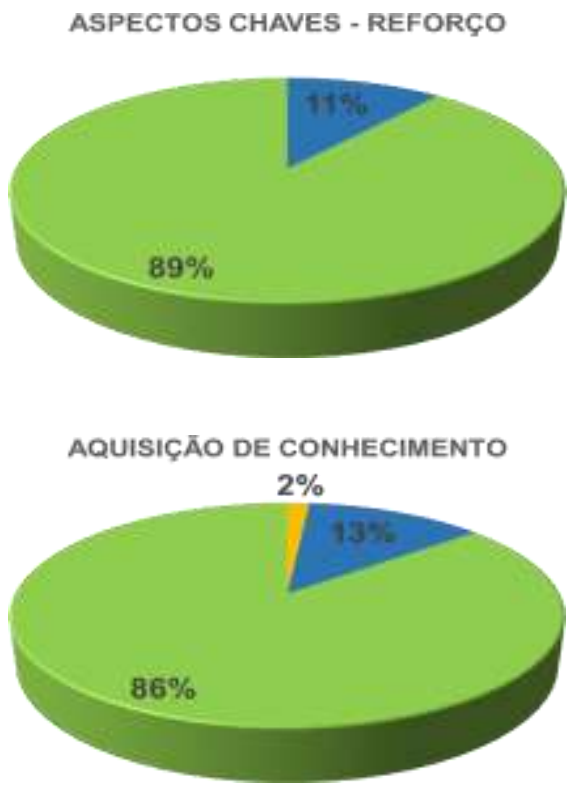

$\because$ DISCORDO $\triangle$ CONCORDO PARCIALMENTE

\section{ESCLARECIMENTO DE DÚVIDAS}

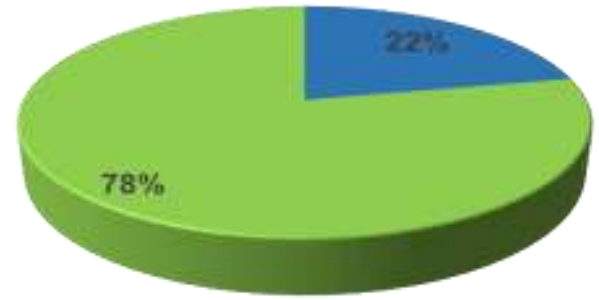

MUDANÇA DE COMPORTAMENTO E ATITUDE

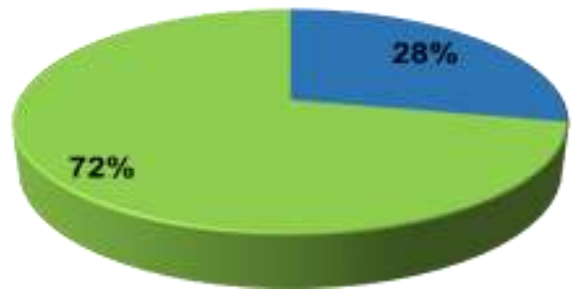

$\triangle$ DISCORDO PARCIALMENTE $\triangle$ CONCORDO

Fonte: Autores (2020).

O cotidiano aliado ao repertório do dia a dia não torna a mudança de comportamento e atitudes fáceis, no entanto ficou nítido para a equipe avaliativa que a resposta para obterem melhores condições no relacionamento escolar vem dessa mudança de comportamento e atitude. Não é um passo fácil, porém a conquista de novas abordagens, de uma nova visão precisa de conduta, é crucial para o diagnóstico claro, bem como para o crescimento e confiança deste aluno original e singular. 
Nas Figuras 6, 7 e 8, os dados foram estratificados para identificar desempenhos diferenciados em função das características da amostragem. Desta maneira, é possível prever aspectos a serem enfatizados em treinamentos futuros, indicando abordagens conforme as características dos participantes.

A Figura 6 relaciona-se com a vivência e experiência do professor em turmas com estudante portador do TDAH. Foram notados percentuais maiores de aceitação dos conceitos aplicados por parte dos avaliadores que não possuíam experiência com o distúrbio. Ficou também perceptível que o esclarecimento de dúvidas e a aquisição de conhecimento foram os pontos que mais divergiram entre os professores que já conseguiam identificar o TDAH nas salas de aula e os que não possuíam essa vivência. Acredita-se que desta forma é demonstrado o sucesso da capacitação, pois os avaliadores puderam refletir sobre as atividades e identificar novos aspectos comportamentais dos estudantes que antes não eram percebidos. Com a falta de preparo das escolas e dos professores para identificarem as necessidades especiais dos estudantes com TDAH, no que diz respeito à aprendizagem, percebe-se fragilidades no desenvolvimento do estudante (Pedroso et al., 2021). Ao implantar os novos conceitos adquiridos, tais informações ajudarão os professores na postura e convivência com o desafio da identificação correta e posterior acompanhamento do estudante.

Para assegurar que os estudantes tenham suas competências voltadas para a aprendizagem, é fundamental que na escola todos tenham conhecimento sobre o transtorno, a fim de não criar barreiras que impeçam que o estudante desenvolva suas habilidades (Flores et al., 2021), os docentes devem manter a atenção à fase de desenvolvimento destas pessoas, a mudanças ambientais ou regras diferentes das de costume, que poderiam causar algum impasse no convívio escolar.

Figura 6 - Estratificação de feedback entre avaliações de profissionais experientes em turmas com portador do TDAH.

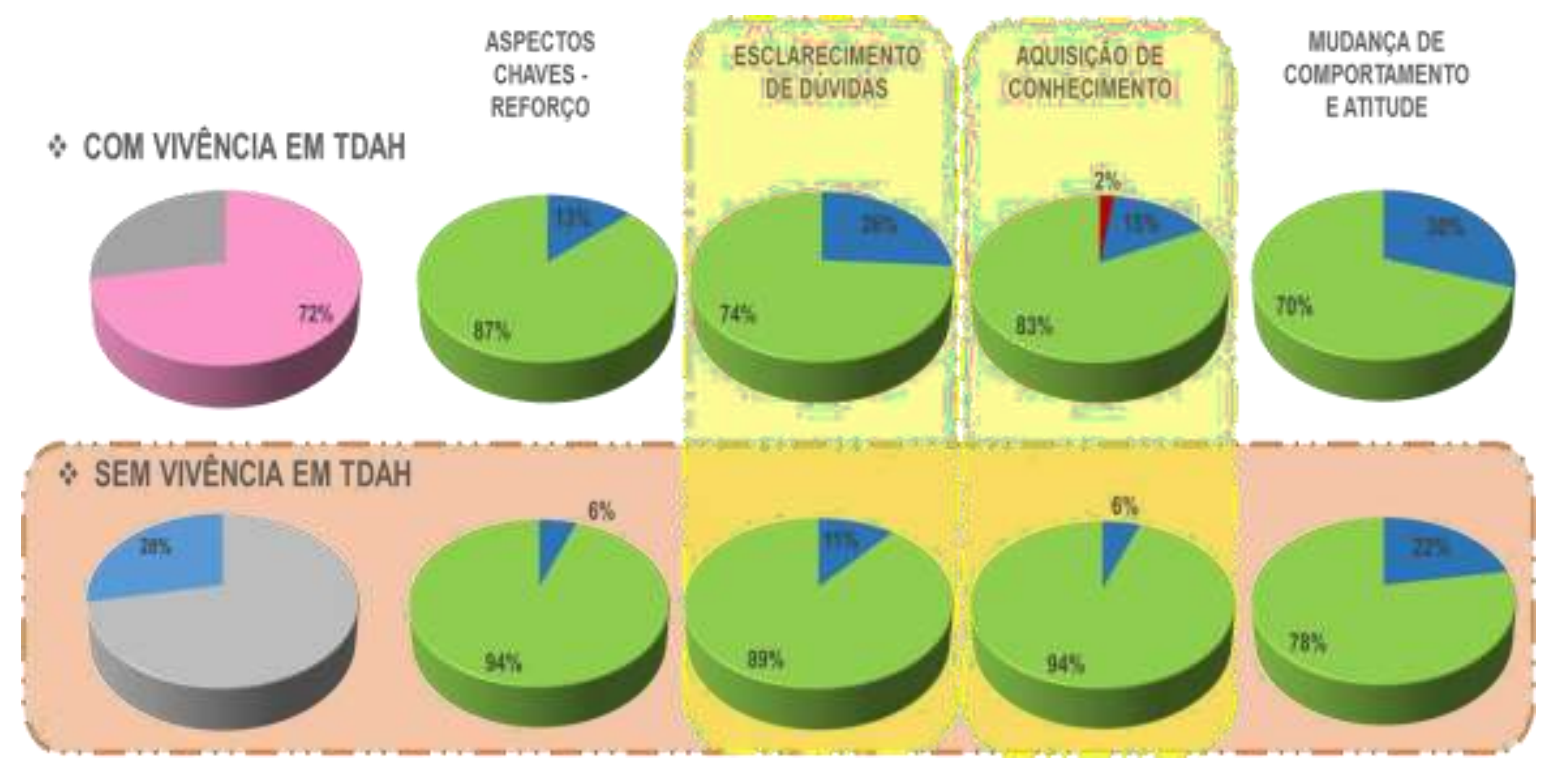

Fonte: Autores (2020).

Já os docentes que conseguiam identificar o TDAH nas classes consideraram que o reforço dos conceitos foi crucial para o desenvolvimento do assunto, segundo explanação dos pontos-chaves que devem ser observados no cotidiano escolar.

O nível de atuação do profissional é um dos aspectos que retratam a diferença entre o comportamento dos estudantes, tendo sido estratificado na Figura 7, que retrata a educação com crianças, adolescentes e adultos, denotando que a satisfação com a capacitação é maior para o nível médio e superior, e apresenta menos concordância para o nível médio e fundamental. O esclarecimento de dúvidas se tornou mais difícil para os profissionais atuantes no ensino médio e 
fundamental, nos quais são encontrados outros comportamentos nos estudantes que podem confundir o professor durante o diagnóstico e atuação. Com isso, a mudança de comportamento e atitude também se torna mais dificultada para tomar ação eficaz sobre a situação que poderá estar acontecendo no cotidiano escolar.

Figura 7 - Estratificação de feedback entre avaliações por níveis de atuação distintos.

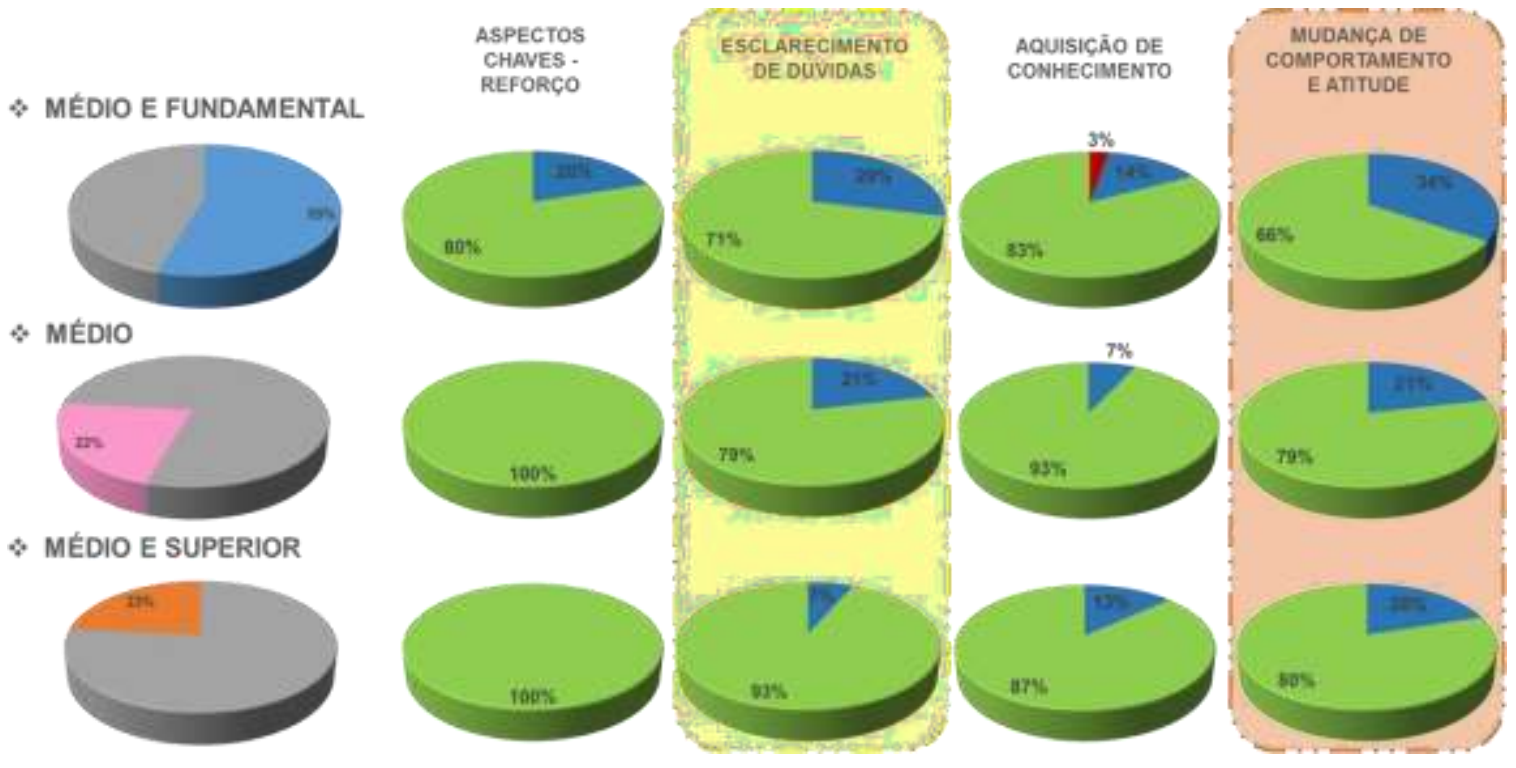

Fonte: Autores (2020).

O tempo de atuação profissional é outro fator que altera a percepção do docente sobre o comportamento do estudante. Deste modo, a Figura 8 exibe primeiramente um diagrama em caixa separando os dados de tempo de atuação em quartis. Conforme Triola (2014), o diagrama de caixa revela a mediana com o centro, a dispersão e a distribuição dos dados. $\mathrm{Na}$ aplicação deste trabalho, a mediana demonstrou que 16 anos é o valor mais encontrado entre os profissionais da amostra, representada pela linha central na caixa, correspondente ao segundo quartil. Os traços laterais da caixa foram estendidos a cada $25 \%$ dos valores dos dados, separando o primeiro e terceiro quartis, implicando que a maioria dos avaliadores possui tempo de atuação entre 10 e 23,3 anos. Porém, alguns indivíduos possuem meses de atuação até o máximo de 35 anos de experiência em docência. 
Figura 8 - Estratificação de feedback entre tempos de atuação profissional distintos.

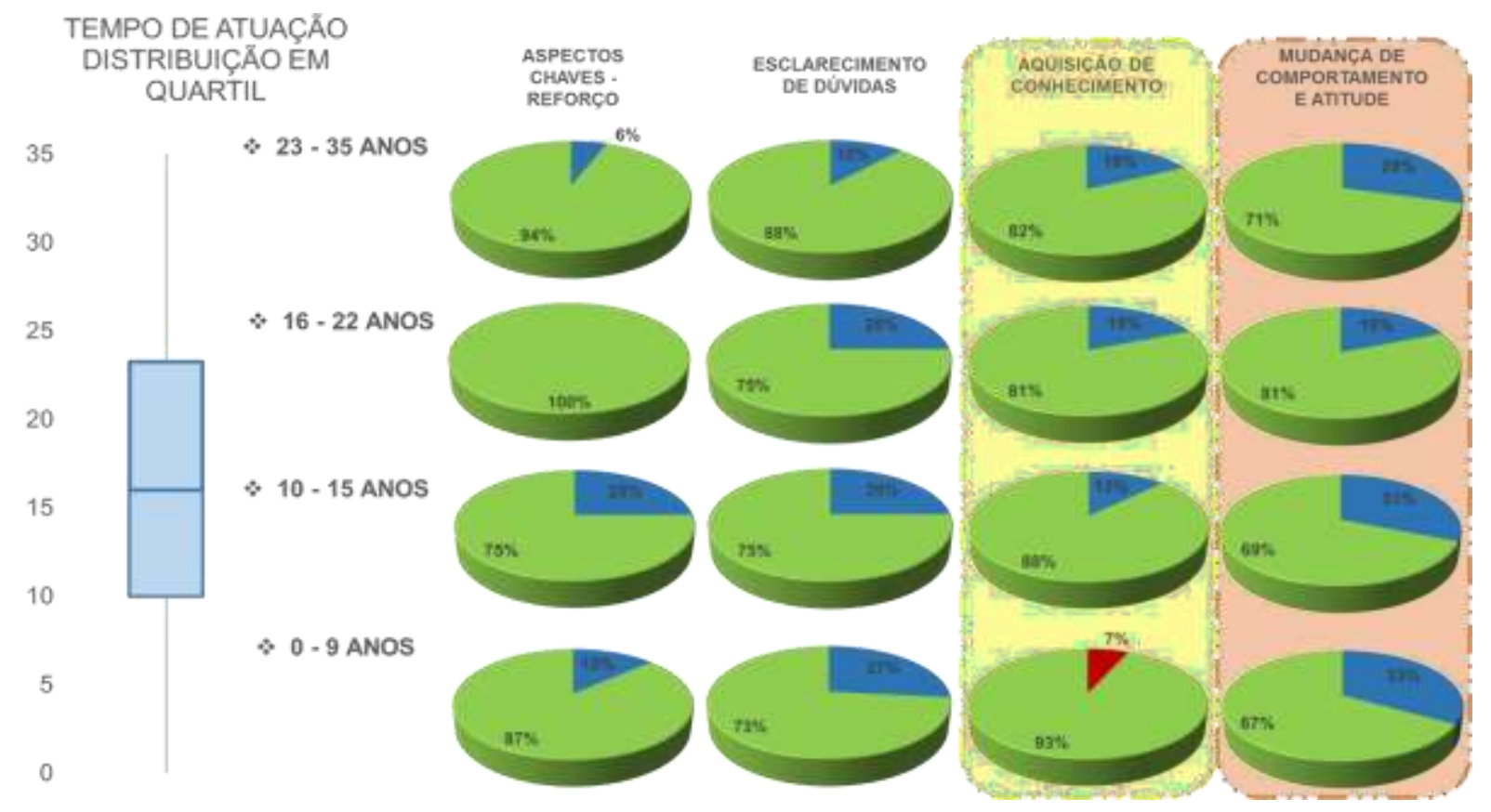

Fonte: Autores (2020).

Os gráficos de setores foram então dispostos de acordo com a avaliação dos quartis da distribuição em caixa e indicam que a mudança de comportamento e atitude teve maior aceitação entre os profissionais com mais tempo de atuação, talvez por sua importância ter sido mais bem entendida devido às diferentes abordagens já aplicadas anteriormente na vida profissional. Consequentemente, caso os próximos treinamentos sejam realizados a docentes com tempo de atuação menor que 16 anos, é relevante enfatizar essa questão e propor atividades para a construção deste pensamento. A aquisição de conhecimento deu-se em caminho contrário, como o esperado, posto que os professores com menor tempo de atuação mostraram-se mais satisfeitos com as atividades.

É possível utilizar outros métodos pedagógicos, além dos habituais, para desafiar os estudantes incluídos a se permitirem a buscar novas formas de aprendizagem a partir da sua vivência e dos recursos digitais disponíveis em nosso meio (Dias et al., 2021). Novas tecnologias e mais pesquisas em benefício ao portador do TDAH são de extrema importância, divulgar outros métodos de conhecimento e informações contribuirão para que o educador tenha um melhor resultado na inclusão dos estudantes com deficiência.

Os resultados obtidos reforçam a importância de compreender os aspectos do comportamento da pessoa com TDAH, por meio do entendimento do transtorno. Contudo, o professor deve assumir o desafio de traduzir e interpretar tais informações de forma correta e ter sensibilidade para percebê-las como fator diferencial no processo de ensino-aprendizagem desse estudante.

Nesta fase, foi possível realizar uma avaliação qualitativa dos dados obtidos, conseguindo-se, assim, resultados de acordo com os objetivos propostos por esta pesquisa, assim como um eixo norteador da relevância do produto educacional. Pretende-se com este estudo suscitar novas pesquisas e a criação de novas tecnologias acerca do TDAH em outros segmentos da educação. Aponta-se a necessidade de que ocorra valorização das mentes criativas que se preocupam em desenvolver tecnologias que aprimorem o cuidado (Balbino et al., 2020) e o conhecimento com vistas à qualidade assistencial e educacional, e que promovem consequentemente a melhora nas condições de trabalho dos profissionais envolvidos na educação. 


\section{Conclusão}

A cartilha, como um suporte para que os professores possam superar dúvidas e dificuldades que permeiam o processo de ensino-aprendizagem do estudante com TDAH contribuirá de forma positiva no aprendizado dos professores, para posterior manejo adequado em sala de aula com o aluno portador do transtorno, além de fomentar novas discussões acerca da temática.

Ao instrumentalizar os educadores do ensino médio por meio de uma ferramenta didática que os auxilie na identificação de estudantes portadores do TDAH possibilitou a construção de conhecimento.

A avaliação dos professores foi fundamental e o processo de avaliação da cartilha educativa foi criterioso em busca de elementos essenciais e dos subsídios necessários, visto que são estes os profissionais que utilizarão este instrumento; assim, são os mais indicados para criticá-lo ou recomendar possíveis alterações.

Pretende-se com este estudo suscitar novas pesquisas acerca do TDAH em outros segmentos da educação.

Os resultados obtidos reforçam a importância de compreender os aspectos do comportamento do estudante portador do TDAH, por meio do entendimento do transtorno. A identificação do transtorno em sala, sem o rotular nem o confundir com falta de limites, é considerada pelos especialistas como "a chave" para o diagnóstico, por ser o professor o primeiro a perceber o transtorno no estudante.

Contudo, o professor deve assumir o desafio de traduzir e interpretar tais informações de forma correta e ter sensibilidade para percebê-las como fator diferencial no processo de ensino-aprendizagem desse estudante.

Diante do grande número de casos diagnosticados de pessoas com esse transtorno e da escassez de informação sobre o tema junto aos educadores, é crucial enfatizar a necessidade de superar o senso comum sobre o Transtorno de Déficit de Atenção e Hiperatividade, conceber a pessoa hiperativa dentro do contexto educacional e a importância da adesão, pelos educadores e familiares, a metodologias significativas para esses estudantes.

\section{Referências}

Arruda, M., Gonçalves, L. T. L., \& Esser, J. F. (2019). O TDAH no contexto escolar: desenvolvimentos da criança na escola frente aos desafios do TDAH e o papel da escola. https://www.fag.edu.br/novo/pg/congressoeducacao/arquivos/2019/O-TDAH-NO-CONTEXTO-ESCOLAR-DESENVOLVIMENTOS-DACRIANCA-NA-ESCOLA-FRENTE-AOS-DESAFIOS-DO-TDAH-E-O-PAPEL-DA-ESCOLA.pdf

Associação Americana de Psiquiatria (2014). Manual diagnóstico e estatístico de transtornos mentais (Recurso Eletrônico) (5a ed.). Artmed. http:// www.niip.com.br/wp-content/uploads/2018/06/Manual-Diagnosico-e-Estatistico-deTranstornos-Mentais-DSM-5-1-pdf.pdf

Associação Brasileira de Déficit de Atenção. Cartilha, A. B. D. A. (2011). TDAH-Transtorno do Déficit de Atenção e hiperatividade: Uma conversa com educadores.

Balbino, C. M., Silvino, Z. R., Joaquim, F. L., Souza, C. J. de, \& Santos, L. M. dos. (2020). Inovação tecnológica: perspectiva dialógica sob a ótica do Joseph Schumpeter. Research, Society and Development, 9(6), e198963593. https://doi.org/10.33448/rsd-v9i6.3593

Carvalho, A. P., \& dos Santos, M. F. R. (2016). TDAH: Da banalização ao diagnóstico. Revista Transformar, 9, $184-202$.

Dias, M. A. M. B., Rosa, R. B., Pedroso, L. V., Pessano, E. F. C., \& Dinardi, A. J. (2021). Metodologias de ensino e a promoção da inclusão de estudantes com Transtorno do Déficit de Atenção e Hiperatividade (TDAH): Uma análise em dissertações e teses da CAPES. Research, Society andDevelopment, 10(9), e18310917840. https://doi.org/10.33448/rsd-v10i9.17840

Flores, J. C., Pedroso, L. V., Puntel, R. L., \& Folmer, V. (2021). Contributos sobre o Transtorno do Déficit de Atenção e Hiperatividade (TDAH) e o processo ensino-aprendizagem da criança do Ensino Fundamental I nos contextos escolar e familiar. Research, Society andDevelopment, 10(8), e21610817170. https://doi.org/10.33448/rsd-v10i8.17170

Maia, M. I. R. \& Confortin, H. (2015). TDAH e aprendizagem: um desafio para a educação. Revista Perspectiva, $39(148), 73-84$.

Martinhago, F., \& Caponi, S. (2019). TDAH em crianças e adolescentes: estudo com professores em uma escola pública do sul do Brasil. Cadernos Brasileiros De Saúde Mental/BrazilianJournalof Mental Health, 11(30), 78-98. https://periodicos.ufsc.br/index.php/cbsm/article/view/69727

Minayo, M. C. S., Deslandes, S. F. \& Gomes, R. (2012). Pesquisa social: teoria, método e criatividade. Vozes. 
Research, Society and Development, v. 10, n. 10, e307101018770, 2021 (CC BY 4.0) | ISSN 2525-3409 | DOI: http://dx.doi.org/10.33448/rsd-v10i10.18770

Pedroso, L. V., Graup, S., Balk, R. de S., Castro, C. J. de, \& Arend, M. H. R. F. (2021). A influência do Transtorno do Déficit de Atenção e Hiperatividade (TDAH) no aprendizado de crianças: Uma Revisão Integrativa da Literatura. Research, Society andDevelopment, 10(7), e16610716354. https://doi.org/10.33448/rsd-v10i7.16354

Pereira, K. A., Eduvirgem, R. V., \& Monteiro, M. L. M. (2017). Problemas Comportamentais de crianças com TDAH no âmbito escolar. Educere-Revista da Educação da UNIPAR, 17(1).

Puhl, C. S., Müller, T. J., \& Lima, I. G. (2020). As contribuições de David Ausubel para os processos de ensino e de aprendizagem. Revista Dynamis. FURB, Blumenau, 26(1)

Reis, P. C. K. R., \& Dalla Cort, F. A. (2016). Filhos com TDAH na visão de mães professoras. Unoesc \& Ciência-ACHS, 7(2), $177-184$.

Rocha, G.A., Loureiro, L. H., \& Ferreira, N. D. F. R. (2020). Transtorno de déficit de atenção e hiperatividade: o educador como foco do cuidado. Revista Eletrônica Científica Ensino Interdisciplinar, 6(16), 149-160.

Rodrigues, I. S. (2018). A violação do princípio da igualdade no tratamento ofertado às crianças com transtorno do deficit de atenção e hiperatividade no ensino fundamental das escolas públicas.

Santos, J. L. A. (2017). TDAH-transtorno de déficit de atenção e hiperatividade: Intervenção psicopedagógica. Ideias e Inovação-Lato Sensu, 4(1), 115-115.

Sodré, M. D. C. (2014). Planejamento organizacional: ações que orientam a gestão democrática da escola.

Triola, M. F. (2014). Introdução à estatística: atualização da tecnologia. In Introdução à estatística: atualização da tecnologia (pp. 707-707). 